\title{
Educational differences in awareness and use of the outpatient smoking cessation services program in Taiwan
}

\author{
Ying-Ting Wang ${ }^{1}$, Hai-Yen Sung ${ }^{2}$, Yi-Wen Tsai*1 \\ ${ }^{1}$ Institute of Health and Welfare Policy, National Yang-Ming University, Taipei, Taiwan \\ ${ }^{2}$ Institute for Health \& Aging, School of Nursing, University of California, San Francisco, California, USA
}

Received: September 25, 2016

Accepted: January 10, 2017

Online Published: February 19, 2017

DOI: $10.5430 /$ ijh.v3n1p50

URL: https://doi.org/10.5430/ijh.v3n1p50

\begin{abstract}
Background: To reduce educational inequalities in smoking, it is important that smoking cessation services can reach lesseducated smokers. Studies on inequalities in awareness or use of smoking cessation services from Asian are lacking. This study assesses educational differences in awareness and use of a nationwide outpatient smoking cessation program in Taiwan.

Methods: A total of 6,461 current smokers aged 25-64 was drawn from cross-sectional nationwide data of the 2012-2014 Adult Smoking Behaviour Survey. Multivariate logistic regression models were used to estimate the association between education and program awareness among current smokers and the association between education and program utilization among current smokers who were aware of the program and attempted to quit in the past 12 months.

Results: About $27 \%$ of current smokers were aware of the program. The odds of being aware of the program were higher for high school graduates $(\mathrm{AOR}=1.38,95 \% \mathrm{CI}=1.02-1.86)$ and those with at least a college degree $(\mathrm{AOR}=1.89,95 \% \mathrm{CI}=1.33-2.70)$, compared to those with middle school or less education. About a quarter of those who were aware of the program and attempted to quit have used the program. There were no educational differences in program utilization.

Conclusions: Given the educational inequalities in awareness of the outpatient program, tobacco-control policies should develop strategies to reach less educated smokers and overcome such inequalities.
\end{abstract}

Key Words: Educational differences, Smoking cessation services, Taiwan

\section{INTRODUCTION}

Tobacco smoking is the leading cause of preventable disease and death, ${ }^{[1]}$ causing nearly 6 million deaths per year worldwide. ${ }^{[2]}$ The disease burden of smoking is disproportionately greater among vulnerable segments of the population that have the highest rates of smoking, such as minorities and those with low levels of education. ${ }^{[1,3-6]}$ This is the case for Taiwan as well. In Taiwan, people with less education are more likely to smoke; for example, among men aged
$25-39,27.9 \%$ of those with at least college education were current smokers, while $48.1 \%$ of high school graduates and $50.3 \%$ of those with middle school or lower education were current smokers in 2012. ${ }^{[7]}$ Furthermore, smoking has even been found to be one of the main underlying mechanisms of educational disparities in health and mortality. ${ }^{[8-14]}$ To mitigate these disparities, it is important that tobacco-control measures and cessation intervention services can reach vulnerable subpopulations. ${ }^{[1,15,16]}$

\footnotetext{
*Correspondence: Yi-Wen Tsai, PhD; Email: ywtsai@ym.edu.tw; Address: No. 155, Section 2, Linong St, Beitou District, Institute of Health and Welfare Policy, National Yang-Ming University, Taipei, Taiwan.
} 
Intuitively, more educated smokers should be more aware of and more likely to use cessation services because they are at better social positions with flexible resources like income and beneficial social connections to avoid risk factors and adopt new information or technology to improve their health. ${ }^{[17]}$ Indeed, studies have found lower education were associated with lower awareness of quitline services in the United States ${ }^{[18]}$ or any cessation services in Taiwan. ${ }^{[19]}$ However, studies on the association between education attainment and use of smoking-cessation services showed mixed results. Some studies found no association between socioeconomic status (SES) and use of cessation services, ${ }^{[18-20]}$ one study found less-educated smokers are more likely to use cessation program than more-educated smokers among those who successfully quitted ${ }^{[21]}$ and one study found no consistent SES pattern in use of different kinds of cessation services. ${ }^{[22]}$

In 2002, the Taiwan government launched a nationwide Outpatient Smoking Cessation Services (OSCS) program, aiming to increase successful smoking cessation among adults aged 19 or older. To encourage more smokers to use the OSCS program, several changes were implemented on March 1, 2012 under the Second Generation Cessation Services Payment Scheme. ${ }^{[23]}$ First, the program extended the smokingcessation treatment services from outpatients only to including hospitalized and emergency care patients as well. Second, doctors can get reimbursements not only for providing combined pharmacotherapy and brief counselling but also for providing stand-alone counselling services. Third, instead of receiving a fixed subsidy for cessation medication, patients now only need to pay a co-payment, capped at NT\$200 (US\$6.40) per prescription (for a four-week supply of medicine). In addition, another $20 \%$ discount is offered for patients living in areas with deficient medical resources, and free medication is provided for low-income families, aborigines, and those living in offshore islands. ${ }^{[23]}$ Little research has been done specifically to examine educational inequalities in awareness or use of nationwide outpatient cessation services program in Asian settings. A recent study focusing on the effect of smoking-cessation media and community campaigns in Taiwan found that smokers with higher education are more likely to be aware of any smoking-cessation services, but there are no educational differences in the use of any assisted quitting methods during 2010 and 2011. ${ }^{[19]}$ However, this study did not separate the OSCS program from other smoking-cessation services or other assisted quitting methods, and this study only covered the period before the 2012 payment scheme.

To evaluate whether all population groups benefitted from the OSCS program's new payment scheme which extended the coverage of smoking-cessation treatment services and

Published by Sciedu Press reduced the cessation medication costs especially for those who are most disadvantaged, this study assesses the educational differences in awareness and use of the OSCS program in Taiwan during 2012-2014. The findings of this study will provide a better understanding of the educational inequalities in awareness and use of smoking-cessation services.

\section{Methods}

\subsection{Data}

All analyses of this study were based on data from the 20122014 Adult Smoking Behaviour Survey (ASBS), which is an annual telephone interview survey conducted by the Health Promotion Administration in Taiwan. It collects information on individuals' smoking behaviours, cessation behaviours, awareness of smoking-cessation services, and use of different cessation methods in Taiwan. The ASBS comprises a nationally representative sample of the noninstitutionalized population aged $\geq 18$ in 2012 and aged $\geq 15$ in 2013 and 2014. This study focused on current smokers defined as those who reported having smoked more than 100 cigarettes during their lifetimes and now smoking cigarettes every day or some days. Because examining educational differences is our main interest and schooling is most likely to be completed by age 25 , we limited the study sample to respondents aged $\geq 25$. To minimize the recall and survivor biases, we did not include older respondents aged $\geq 65$. The pooled 2012-2014 ASBS data contain 6,461 current smokers aged 25-64.

\subsection{Outcome variables}

Two outcome variables were examined: awareness of the OSCS and use of the OSCS. Awareness of the OSCS is a dichotomous variable measured for all current smokers by a multiple-choice question: "Are you aware of any cessation services that health organizations provide?" Respondents whose answers included the OSCS program were assigned the value 1 to the awareness variable. Respondents whose answers did not include the OSCS program but included other cessation services, such as smoking-cessation classes, quitline, and pharmacy cessation consultation services or who answered that they were "not aware of any cessation services" or "don't know", were assigned the value 0 . Those who refused to answer were excluded from the awareness analysis.

Use of the OSCS was a dichotomous variable measured only for current smokers who had made a quit attempt in the past 12 months by a multiple-choice question: "During the past 12 months, what kinds of quitting methods did you use?" Those whose answers included the OSCS program were assigned the value 1 to the use variable, while those who answered 
other methods such as quitline, "no method" or "don't know" were assigned the value 0 . Those who refused to answer were excluded from the OSCS utilization analysis.

\subsection{Covariates}

Education level was classified into three categories: middle school or lower, high school, and college or higher. Other covariates include survey year (2012, 2013, and 2014), gender (female, male), age (24-34, 35-44, 45-54, and 55-64), marital status (married, not married), monthly household income (< NT\$20,000, NT\$20,001-60,000, NT\$60,001-100,000, $>$ NT\$100,000, and unknown), employment status (employed, not employed), ethnicity (aboriginal, non-aboriginal), residential location (municipalities, non-municipalities), selfrated health (poor/bad, very good/good/fair), visitations to health professionals (in the past 12 months, not in the past 12 months), nicotine dependence (smoked first cigarette $\leq 30$ minutes, and $>30$ minutes after waking), smoking frequency (daily smokers, non-daily smokers), and quit attempts (attempted to quit in the last 12 months, did not attempt to quit in the last 12 months). The "not married" group included those who are single, divorced, separated, widowed, or living with an unmarried partner. Respondents who did not report household income were classified as a separate "unknown" group. Health professional visits were measured by the question: "During the past 12 months, did you visit any health providers such as physicians, dentists, nurses or pharmacists?" Nicotine dependence was measured by a question asking smokers, "In the past 30 days, when did you usually smoke your first cigarette after waking?"[24] Quit attempts were measured by a question asking current smokers, "During the past 12 months, did you ever stop smoking for 1 day or longer because you were trying to quit smoking?" For the analyses on the use of the OSCS, we excluded quit attempts as a covariate.

\subsection{Statistical analysis}

Stata software (version 12.1, College Station, TX) was used to conduct all analyses. All estimates were weighted by the sampling weights, which adjust for respondents' probability of being selected and match the compositions of gender, age, education level, and municipality residency with the census population. Awareness of the OSCS program was analysed among all current smokers aged 25-64. Use of the OSCS program was analysed among current smokers aged 25-64 who had made a quite attempt in the past 12 month and were aware of the OSCS program. We estimated the prevalence of each outcome variable by each covariate, and examined the association between the outcome variable and each covariate using the chi-square test for bivariate analyses. The multivariate logistic regression analysis was conducted to examine the association between education level and each outcome variable, while controlling for those covariates which show statistical significance from the bivariate analysis. The adjusted odds ratio and $95 \%$ confidence interval were computed to assess the strength of association. We determined statistical significance when the two-tailed $p$-value $<.05$.

\subsection{Final study sample}

After excluding 93 cases with missing values for the awareness variable and 399 cases with missing values for other covariates, we obtained 5,969 current smokers for multivariate regression analyses on the awareness of the OSCS program. We further excluded those who did not attempt to quit in the past 12 months $(\mathrm{N}=3,721)$ and those who were not aware of the program $(\mathrm{N}=1,461)$ to result in 787 smokers for multivariate regression analyses on the use of the OSCS program.

\section{RESUltS}

\subsection{Sample description}

Table 1 shows the sample distribution for our sample, current smokers aged 25 to 64 . Of the sample, $24.8 \%$ had middle school or lower education and $31.8 \%$ had at least a college degree. Most of the sample were male (89.0\%), aged $35-44(35.2 \%)$, married $(60.3 \%)$, with monthly household NT\$20,001-60,000 (43.6\%), employed (80.6\%), not aboriginal (96.6\%), living in municipalities (53.9\%), and not in poor/bad health $(82.3 \%)$. Slightly over half of them visited health professionals in the past 12 months and smoked their first cigarette within 30 minutes after waking. Majority $(82.0 \%)$ of them are daily smokers, and about one third of them attempted to quit in the past 12 months.

\subsection{Education level and awareness of the OSCS pro- gram}

Slightly more than a quarter $(26.5 \%)$ of current smokers were aware of the OSCS program (see Table 2). Prevalence of being aware of the OSCS program differed by education level: $20.6 \%, 28.1 \%$ and $35.8 \%(p<.001)$ among those with middle school or lower education, high school graduates, and those with college or higher education, respectively. The multivariate regression results showed that awareness of the OSCS program was positively associated with education level (see Table 3 ). The odds of being aware of the OSCS program were $38 \%$ higher for high school graduates $(\mathrm{AOR}=1.38,95 \% \mathrm{CI}=1.02-1.86)$ and $89 \%$ higher for those with at least a college degree $(\mathrm{AOR}=1.89$, $95 \% \mathrm{CI}=1.33-2.70$ ), compared to those with middle school or less education. In addition, awareness of the OSCS program was more likely in 2014 than in 2012, among younger groups than the oldest group, among those who visited a 
health professional in the past 12 months than those who did not, and among those had quit attempts in the past 12 months than those who did not.

Table 1. Sample distribution by covariates among current smokers aged 25 to 64, Taiwan, 2012-2014

\begin{tabular}{|c|c|}
\hline & Column \% \\
\hline \multicolumn{2}{|l|}{ Education } \\
\hline Middle School or lower & 24.8 \\
\hline High School & 43.4 \\
\hline College or higher & 31.8 \\
\hline \multicolumn{2}{|l|}{ Year } \\
\hline 2012 & 27.1 \\
\hline 2013 & 38.8 \\
\hline 2014 & 34.1 \\
\hline \multicolumn{2}{|l|}{ Gender } \\
\hline Male & 89.0 \\
\hline Female & 11.0 \\
\hline \multicolumn{2}{|l|}{ Age } \\
\hline $55-64$ & 11.6 \\
\hline $45-54$ & 24.6 \\
\hline $35-44$ & 35.2 \\
\hline $25-34$ & 28.5 \\
\hline \multicolumn{2}{|l|}{ Marital Status } \\
\hline Not married & 39.7 \\
\hline Married & 60.3 \\
\hline \multicolumn{2}{|l|}{ Household income (monthly) } \\
\hline$\leq \mathrm{NT} \$ 20,000$ & 9.8 \\
\hline NT\$20,001-60,000 & 43.6 \\
\hline NT\$60,001-100,000 & 16.7 \\
\hline$>$ NT\$100,000 & 11.9 \\
\hline Unknown & 18.0 \\
\hline \multicolumn{2}{|l|}{ Employment status } \\
\hline Employed & 80.6 \\
\hline \multicolumn{2}{|l|}{ Not employed } \\
\hline \multicolumn{2}{|l|}{ Ethnicity } \\
\hline Aboriginal & 3.4 \\
\hline Non-aboriginal & 96.6 \\
\hline \multicolumn{2}{|l|}{ Residential location } \\
\hline Municipalities & 53.9 \\
\hline Non-municipalities & 46.1 \\
\hline \multicolumn{2}{|l|}{ Self-rated health } \\
\hline Poor/bad & 17.7 \\
\hline Very good/good/fair & 82.3 \\
\hline \multicolumn{2}{|l|}{ Visitations to health professionals } \\
\hline Not in the past 12 months & 45.2 \\
\hline In the past 12 months & 54.8 \\
\hline \multicolumn{2}{|l|}{ Time to first cigarette after waking } \\
\hline$\leq 30$ & 56.6 \\
\hline$>30$ minutes & 43.4 \\
\hline \multicolumn{2}{|l|}{ Smoking frequency } \\
\hline Daily smokers & 82.0 \\
\hline Non-daily smokers & 18.0 \\
\hline \multicolumn{2}{|l|}{ Quit attempts } \\
\hline Did not attempted to quit in the past 12 months & 65.2 \\
\hline Attempted to quit in the past 12 months & 34.8 \\
\hline
\end{tabular}

Table 2. Prevalence of OSCS awareness among current smokers aged 25 to 64 , Taiwan, 2012-2014, $\mathrm{N}=5,969$

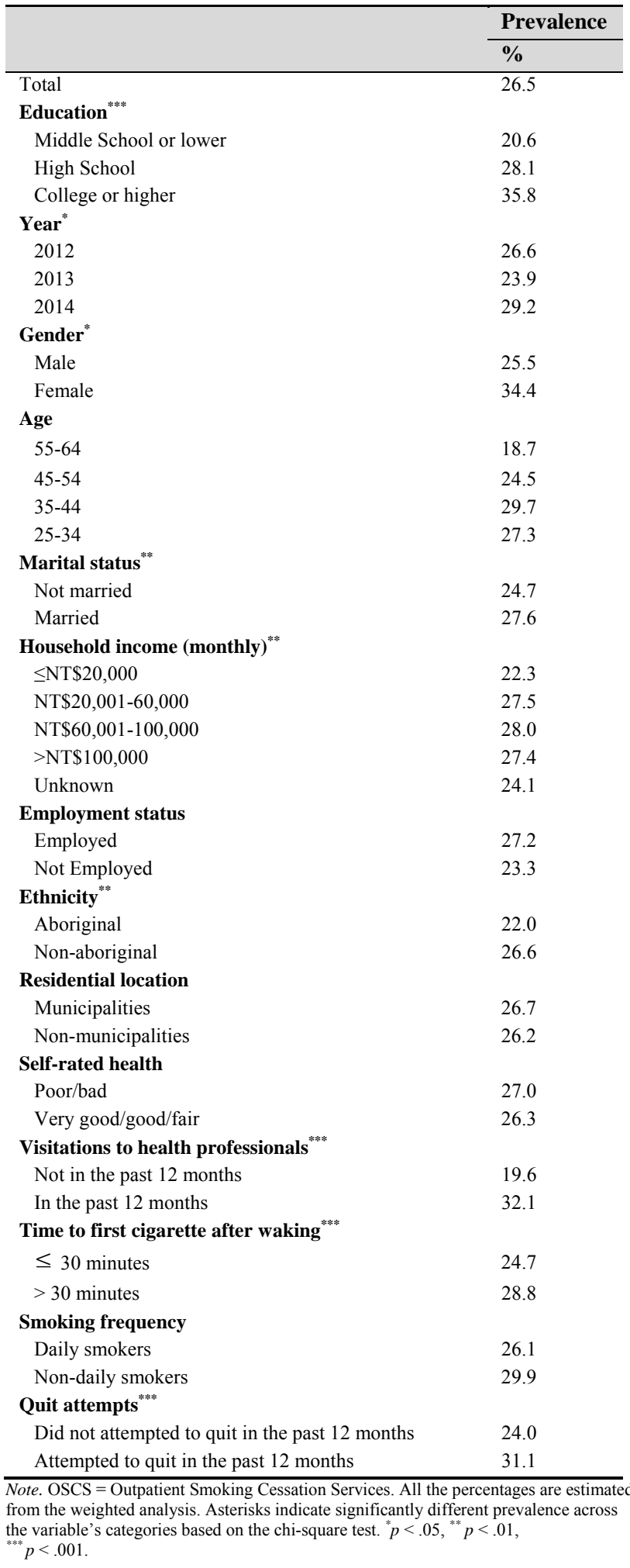

\subsection{Education level and use of the OSCS program}

About a quarter $(24.5 \%)$ of current smokers who had quit attempts in the past 12 months and were aware of the pro- 
gram had used the OSCS program (see Table 4). The use of the OSCS program did not differ by education level in the bivariate chi-square test. The prevalence of use of the OSCS significantly differed by survey year, household income, visitation to health professionals, and time to first cigarette after waking in the bivariate chi-square test. Yet, in the multivariate logistic regression (see Table 5), only visitation to health professionals was significantly associated with use of the OSCS: the odds of using the OSCS program in the past 12 months were significantly higher among those who visited a health professional in the past 12 months than those who did $\operatorname{not}(\mathrm{AOR}=4.49,95 \% \mathrm{CI}=2.22-9.07)$.

Table 3. Adjusted odds ratios from a multivariate logistic regression model among current smokers aged 25 to 64 , Taiwan, 2012-2014, N = 5,969

\begin{tabular}{|c|c|c|}
\hline & AOR & $(95 \% \mathrm{CI})$ \\
\hline \multicolumn{3}{|l|}{ Education } \\
\hline Middle School or lower (ref.) & 1.00 & \\
\hline High School & 1.38 & $(1.02,1.86)^{*}$ \\
\hline College or higher & 1.89 & $(1.33,2.70)^{* * *}$ \\
\hline \multicolumn{3}{|l|}{ Year } \\
\hline 2012 (ref.) & 1.00 & \\
\hline 2013 & 0.96 & $(0.75,1.24)$ \\
\hline 2014 & 1.24 & $(0.96,1.61)$ \\
\hline \multicolumn{3}{|l|}{ Gender } \\
\hline Male (ref.) & 1.00 & \\
\hline Female & 1.48 & $(0.99,2.20)$ \\
\hline \multicolumn{3}{|l|}{ Age } \\
\hline 55-64 (ref.) & 1.00 & \\
\hline $45-54$ & 1.31 & $(0.93,1.84)$ \\
\hline $35-44$ & 1.56 & $(1.07,2.28)^{*}$ \\
\hline $25-34$ & 1.41 & $(0.95,2.10)$ \\
\hline \multicolumn{3}{|l|}{ Marital status } \\
\hline Not married (ref.) & 1.00 & \\
\hline Married & 1.19 & $(0.93,1.51)$ \\
\hline \multicolumn{3}{|l|}{ Household income (monthly) } \\
\hline$\leq \mathrm{NT} \$ 20,000$ (ref.) & 1.00 & \\
\hline NT\$20,001-60,000 & 1.18 & $(0.78,1.79)$ \\
\hline NT\$60,001-100,000 & 0.99 & $(0.62,1.59)$ \\
\hline$>\mathrm{NT} \$ 100,000$ & 0.90 & $(0.55,1.49)$ \\
\hline Unknown & 0.94 & $(0.57,1.55)$ \\
\hline \multicolumn{3}{|l|}{ Ethnicity } \\
\hline Aboriginal (ref.) & 1.00 & \\
\hline Non-aboriginal & 1.29 & $(0.72,2.31)$ \\
\hline \multicolumn{3}{|l|}{ Visitations to health professionals } \\
\hline Not in the past 12 months (ref.) & 1.00 & \\
\hline In the past 12 months & 1.89 & $(1.51,2.37)^{* * *}$ \\
\hline \multicolumn{3}{|l|}{ Time to first cigarette after waking } \\
\hline$\leq 30$ minutes (ref.) & 1.00 & \\
\hline$>30$ minutes & 1.07 & $(0.86,1.34)$ \\
\hline \multicolumn{3}{|l|}{ Quit attempts } \\
\hline $\begin{array}{l}\text { Did not attempted to quit in the past } 12 \text { months } \\
\text { (ref.) }\end{array}$ & 1.00 & \\
\hline Attempted to quit in the past 12 months & 1.42 & $(1.14,1.77)^{* *}$ \\
\hline
\end{tabular}

\section{Discussion}

Using a national representative data from Taiwan, our study showed significant educational inequalities in awareness of the OSCS program among current smokers aged 25 to 64 in Taiwan during 2012 to 2014. This result is consistent with findings from previous studies showing that higher education is associated with higher awareness of the quitline services in the United States ${ }^{[18]}$ and any cessation services in Taiwan during 2010 and 2011. ${ }^{[19]}$ Different from previous studies, our study adds to the literature by providing evidences for the association between education level and a nationwide outpatient smoking-cessation program in an Asian setting. The association between education level and awareness of the OSCS program might be because highly educated people have high health literacy in Taiwan, ${ }^{[25,26]}$ and thus they have the capacity to access information on medical issues, resources, and, in our case, smoking cessation services.

Table 4. Prevalence of OSCS usage among current smokers aged 25 to 64 who attempted to quit in the past 12 months and reported awareness of the program, Taiwan, 2012-2014, $\mathrm{N}=787$

\begin{tabular}{|c|c|}
\hline & Prevalence \\
\hline & $\%$ \\
\hline Total & 24.5 \\
\hline \multicolumn{2}{|l|}{ Education } \\
\hline Middle School or lower & 25.0 \\
\hline High School & 23.4 \\
\hline College or higher & 25.9 \\
\hline \multicolumn{2}{|l|}{ Year** $^{*}$} \\
\hline 2012 & 19.3 \\
\hline 2013 & 23.7 \\
\hline 2014 & 29.7 \\
\hline \multicolumn{2}{|l|}{ Gender } \\
\hline Male & 23.3 \\
\hline Female & 33.9 \\
\hline \multicolumn{2}{|l|}{ Age } \\
\hline $55-64$ & 34.3 \\
\hline $45-54$ & 19.2 \\
\hline $35-44$ & 24.9 \\
\hline $25-34$ & 25.7 \\
\hline \multicolumn{2}{|l|}{ Marital status } \\
\hline Not married & 20.3 \\
\hline Married & 26.6 \\
\hline \multicolumn{2}{|c|}{ Household income (monthly) ${ }^{* *}$} \\
\hline$\leq \mathrm{NT} \$ 20,000$ & 27.4 \\
\hline NT\$20,001-60,000 & 21.4 \\
\hline NT\$60,001-100,000 & 28.3 \\
\hline$>$ NT\$100,000 & 32.1 \\
\hline Unknown & 22.0 \\
\hline \multicolumn{2}{|l|}{ Employment status } \\
\hline Employed & 25.0 \\
\hline Not Employed & 21.9 \\
\hline \multicolumn{2}{|l|}{ Ethnicity } \\
\hline Aboriginal & 11.9 \\
\hline Non-aboriginal & 24.9 \\
\hline \multicolumn{2}{|l|}{ Residential location } \\
\hline Municipalities & 26.2 \\
\hline Non-municipalities & 23.0 \\
\hline \multicolumn{2}{|l|}{ Self-rated health } \\
\hline Poor/bad & 20.1 \\
\hline Very good/good/fair & 25.7 \\
\hline \multicolumn{2}{|c|}{ Visitations to health professionals ${ }^{* * *}$} \\
\hline Not in the past 12 months & 9.7 \\
\hline In the past 12 months & 32.1 \\
\hline \multicolumn{2}{|c|}{ Time to first cigarette after waking ${ }^{* * * *}$} \\
\hline$\leq 30$ minutes & 29.7 \\
\hline$>30$ minutes & 19.7 \\
\hline \multicolumn{2}{|l|}{ Smoking frequency } \\
\hline Daily smokers & 23.8 \\
\hline Non-daily smokers & 28.5 \\
\hline
\end{tabular}

Among smokers who were aware of the OSCS program and attempted to quit in the past 12 months, we found no significant association between education level and use of the OSCS program. In fact, there were no differences in use of the program by employment status and household income 
either. These findings, along with few existing studies, ${ }^{[18-20]}$ show evidences that there were no association between SES and use of cessation services. The equal use of the OSCS program could be because disadvantaged patients can receive discount on the medication or even free medication, ${ }^{[23]}$ which makes the program more affordable for disadvantaged patients. Nevertheless, further studies are needed to examine how the reduced cost of medication affect smokers intention to use the OSCS program and the association between SES and use of the program.

Table 5. Adjusted odds ratios from a multivariate logistic regression model among current smokers aged 25 to 64 who attempted to quit in the past 12 months and reported awareness of the program, Taiwan, 2012-2014, N = 787

\begin{tabular}{lcc}
\hline & AOR & $(\mathbf{9 5 \%}$ CI) \\
\hline Year & & \\
2012 (ref.) & 1.00 & \\
2013 & 1.37 & $(0.62,3.04)$ \\
$\quad 2014$ & 1.69 & $(0.77,3.72)$ \\
$\quad$ Household income (monthly) & & \\
$\quad \leq$ NT\$20,000 (ref.) & 1.00 & \\
$\quad$ NT\$20,001-60,000 & 0.88 & $(0.24,3.18)$ \\
$\quad$ NT\$60,001-100,000 & 1.43 & $(0.39,5.29)$ \\
$\quad>$ NT\$100,000 & 1.16 & $(0.29,4.69)$ \\
$\quad$ Unknown & 0.87 & $(0.22,3.39)$ \\
$\quad$ Visitations to health professionals & & \\
$\quad$ Not in the past 12 months (ref.) & 1.00 & \\
$\quad$ In the past 12 months & 4.49 & $(2.22,9.07)$ \\
$\quad$ Time to first cigarette after waking & & \\
$\quad \leq 30$ minutes (ref.) & 1.00 & \\
$\quad>30$ minutes & 0.61 & $(0.33,1.13)$
\end{tabular}

Note. AOR = adjusted odds ratio; $\mathrm{CI}=$ confidence interval; OSCS = Outpatient Smoking Cessation Services. ${ }^{* * *} p<.001$.

The finding of equal use of OSCS program should be interpreted with caution; given that awareness is the precursor of utilization, there may still be latent educational inequalities in use of the program because many less-educated smokers were simply unaware of the program. Since nontargeted smoking-cessation programs appear to exacerbate socioeconomic inequality in smoking as found in a systematic review of the literature, ${ }^{[27]}$ policy makers should make extra efforts to target and reach disadvantaged smokers when designing smoking-cessation services. Furthermore, even if there were equal use of the OSCS program, whether different users of the OSCS program have the same smoking-cessation success rate is unclear. Some studies have shown that low-SES users of the cessation services have a lower quit rate than their high-SES counterparts. ${ }^{[27-29]}$ To our knowledge, there has been no empirical study to evaluate the impact of using the OSCS program on the success of smoking cessation by education level. This topic is beyond the scope of the present

Published by Sciedu Press study and warrants further research.

In addition to targeting the socioeconomically disadvantaged smokers, Taiwan government should make efforts to increase the overall awareness of the OSCS program as well. During 2012-2014, only approximately one quarter of smokers in Taiwan were aware of the OSCS program, and about one quarter of those who were aware of the program had used the program in the past 12 months. Therefore, implementing effective public education programs and strategic advertising campaigns to increase the awareness of the OSCS program among smokers would significantly increase the use of this program. To improve awareness of the OSCS program, the government should keep using mass media for large scale campaigns, especially community-based campaigns, as they were found to be effective methods for informing smokers about cessation services in previous studies in Taiwan and elsewhere. ${ }^{[19,30,31]}$ More importantly, the messages of mass media campaigns should be tailored, addressing barriers of using the services and expanding the outreach to specific demographic groups, as these two approaches were suggested to improve enrolment of a phone-based smoking cessation services. ${ }^{[30]}$ Furthermore, our results that having health professional visits was positively associated with awareness and use of the OSCS program imply that health professionals might have played an important role in contributing to disseminating the information about the OSCS program to their smoking patients and even referring them to use the OSCS program. Thus, it is important to keep involving all health professionals in promoting the OSCS program.

This study has some limitations. First, the ASBS is a selfreported telephone survey and thus may be subject to recall and measurement bias. Second, the ASBS was conducted through landlines, and therefore this study might not capture people who only use cell phones (about $6.2 \%$ of adults aged 20 years or older in Taiwan). ${ }^{[32]}$ Third, like most telephone surveys, the response rate of the ASBS was only about $60 \%$, and this might produce some selection bias. Fourth, the ASBS is a cross-sectional survey; therefore, our results can only indicate associations, not causalities. For example, visiting health professionals is associated with higher odds of awareness and use of the OSCS program, but we do not know whether the respondents knew about or used the OSCS program before or after visiting their health professionals. Finally, it is not clear whether the respondents might count their visits for getting the cessation treatment from the OSCS program as a visit to a health professional.

\section{Conclusion}

Despite the above-mentioned limitations, this is the first study, to our knowledge, to specially investigate the edu- 
cational inequality in awareness and use of a nationwide outpatient smoking-cessation program in an Asian setting. Our findings add to the literature by showing that although there were no educational inequalities in use of Taiwan's nationwide outpatient smoking cessation services program which was more comprehensive and more affordable under the new payment scheme, there were significant education inequalities in awareness of the program during 2012 2014. Because awareness is the precursor of utilization, there may still be inequalities in use of the program since many less-educated smokers were simply unaware of the program. Therefore, future tobacco-control policies should recognize the educational inequalities in awareness of outpatient smoking-cessation services and develop effective dis-

\section{REFERENCES}

[1] U.S. Department of Health and Human Services. (2014). The Health Consequences of Smoking-50 Years of Progress: A Report of the Surgeon General Retrieved from: http://www . surgeongeneral.gov/library/reports/50-y ears-of-progress/full-report.pdf

[2] World Health Organization. WHO Report on the Global Tobacco Epidemic, 2011: Warning About The Dangers of Tobacco Retrieved from: http://www.who.int/tobacco/global_report/ 2011/en/

[3] Hiscock R, Bauld L, Amos A, et al. Socioeconomic status and smoking: a review. Annals of the New York Academy of Sciences. 2012; 1248(1): 107-23. https://doi.org/10.1111/j.1749-6632.20 $11.06202 . \mathrm{x}$

[4] Max W, Sung HY, Tucker LY, et al. The disproportionate cost of smoking for African Americans in California. American Journal of Public Health. 2010; 100(1): 152-8. https://doi.org/10.2105/ AJPH . 2008.149542

[5] Trinidad DR, Pérez-Stable EJ, White MM, et al. A nationwide analysis of US racial/ethnic disparities in smoking behaviors, smoking cessation, and cessation-related factors. American Journal of Public Health. 2011; 101(4): 699-706. https://doi.org/10.2105/AJ PH. 2010. 191668

[6] U.S. Department of Health and Human Services. (1998). Tobacco Use Among U.S. Racial/Ethnic Minority Groups-African Americans, American Indians and Alaska Natives, Asian Americans and Pacific Islanders, and Hispanics: A Report of the Surgeon General Retrieved from: http://www.cdc.gov/tobacco/data_statistics/sg r/1998/complete_report/pdfs/complete_report.pdf

[7] Health Promotion Administration, \& Ministry of Health and Welfare R.O.C.(Taiwan). Taiwan Tobacco Control Annual Report 2013. 2014 Available from: http://tobacco.hpa.gov.tw/Show.aspx?Men $\mathrm{uId}=412$

[8] Denney JT, Rogers RG, Hummer RA, et al. Education inequality in mortality: the age and gender specific mediating effects of cigarette smoking. Social Science Research. 2010; 39(4): 662-73. https://doi.org/10.1016/j.ssresearch.2010.02.007

[9] Ho JY, Fenelon A. The contribution of smoking to educational gradients in U.S. life expectancy. Journal of Health and Social Behavior. semination strategies to reach less educated smokers and overcome such inequalities.

\section{ACKNOWLEDGEMENTS}

National Yang-Ming University received research funding from the tobacco health and welfare surcharges by the Health Promotion Administration for project titled International Collaborative Project for the Evaluation of Medical Services for Smoking Cessation (G1031227-105). The content of this article is solely the responsibility of the authors and does not necessarily represent the official views of the funding agency.

\section{CONFLICTS OF INTEREST DisClOSURE}

The authors declare no conflicts of interest.
2015; 56(3): 307-22. https://doi.org/10.1177/0022146515 592731

[10] Jha P, Peto R, Zatonski W, et al. Social inequalities in male mortality, and in male mortality from smoking: indirect estimation from national death rates in England and Wales, Poland, and North America Lancet. 2006; 368(9533): 367-70. https://doi.org/10.1016/ S0140-6736 (06) 68975-7

[11] Koch MB, Diderichsen F, Gronbaek M, et al. What is the association of smoking and alcohol use with the increase in social inequality in mortality in Denmark? A nationwide register-based study. BMJ Open. 2015; 5(5): e006588. https://doi.org/10.1136/bmjope $\mathrm{n}-2014-006588$

[12] Meara ER, Richards S, Cutler DM. The gap gets bigger: changes in mortality and life expectancy, by education, 1981-2000. Health Affairs. 2008; 27(2): 350-60. https://doi.org/10.1377/hlth aff .27 .2 .350

[13] Mirowsky J, Ross CE. Education, Social Status and Health. New York: Aldine De Gruyter. 2003. PMid: 12502867.

[14] Ross CE, Wu CL. The links between education and health. American Sociological Review. 1995; 60(5): 719-45. https ://doi.org/10 $.2307 / 2096319$

[15] Garrett BE, Dube SR, Babb S, et al. Addressing the social determinants of health to reduce tobacco-related disparities. Nicotine \& Tobacco Research. 2015; 17(8): 892-7. https://doi.org/10.1 093/ntr/ntu266

[16] Murray RL, Bauld L, Hackshaw LE, et al. Improving access to smoking cessation services for disadvantaged groups: a systematic review. Journal of Public Health. 2009; 31(2): 258-77. PMid: 19208688. https://doi.org/10.1093/pubmed/fdp008

[17] Link BG, Phelan J. Social Conditions As Fundamental Causes of Disease. Journal of Health and Social Behavior. 1995; 35: 80-94. https://doi.org/10.2307/2626958

[18] Schauer GL, Malarcher AM, Zhang L, et al. Prevalence and correlates of quitline awareness and utilization in the United States: an update from the 2009-2010 National Adult Tobacco Survey. Nicotine \& Tobacco Research. 2014; 16(5): 544-53. https://doi.org/10 .1093/ntr/ntt181

[19] Chang FC, Sung HY, Zhu SH, et al. Effects of smoking cessation media and community campaigns in Taiwan. American Journal of 
Health Promotion. 2015. https://doi.org/10.4278/ajhp.140 922-QUAN-457

[20] Kotz D, West R. Explaining the social gradient in smoking cessation: It's not in the trying, but in the succeeding. Tobacco Control. 2009; 18(1): 43-6.

[21] Lillard DR, Plassmann V, Kenkel D, et al. Who kicks the habit and how they do it: socioeconomic differences across methods of quitting smoking in the USA. Social Science and Medicine. 2007; 64(12): 2504-19. https://doi.org/10.1016/j. socscimed. 20 07.02 .036

[22] Clare P, Slade T, Courtney RJ, et al. Use of smoking cessation and quit support services by socioeconomic status over 10 years of the national drug strategy household survey. Nicotine \& Tobacco Research. 2014; 16(12): 1647-55. https://doi.org/10.1093/ntr/ntu119

[23] Health Promotion Administration, \& Ministry of Health and Welfare R.O.C.(Taiwan). Taiwan Tobacco Control Annual Report 2014. 2015. Available from: http://tobacco.hpa.gov.tw/Show.aspx?Men $\mathrm{uId}=412$

[24] Heatherton TF, Kozlowski LT, Frecker RC, et al. The Fagerström test for nicotine dependence: a revision of the Fagerström Tolerance Questionnaire. British Journal of Addiction. 1991; 86(9): 1119-27. https://doi.org/10.1111/j.1360-0443.1991.tb01879.x

[25] Duong VT, Lin IF, Sorensen K, et al. Health Literacy in Taiwan: A Population-Based Study. Asia-Pacific Journal of Public Health. 2015; 27(8): 871-80. https://doi.org/10.1177/1010539515 607962
[26] Lee SYD, Tsai TI, Tsai YW, et al. Health literacy, health status, and healthcare utilization of Taiwanese adults: results from a national survey. BMC Public Health. 2010; 10(1): 1-8. https : //doi.org/10.1186/1471-2458-10-614

[27] Hill S, Amos A, Clifford D, et al. Impact of tobacco control interventions on socioeconomic inequalities in smoking: review of the evidence. Tobacco Control. 2014; 23(e2): e89-e97. https: //doi.org/10.1136/tobaccocontrol-2013-051110

[28] Hiscock R, Judge K, Bauld L. Social inequalities in quitting smoking: what factors mediate the relationship between socioeconomic position and smoking cessation? Journal of Public Health. 2011; 33(1): 39-47. https://doi.org/10.1093/pubmed/fdq097

[29] Sheffer CE, Stitzer M, Landes R, et al. Socioeconomic disparities in community-based treatment of tobacco dependence. American Journal of Public Health. 2012; 102(3): e8-16. https ://doi .org/ 10.2105/AJPH. 2011.300519

[30] Czarnecki KD, Vichinsky LE, Ellis JA, et al. Media campaign effectiveness in promoting a smoking-cessation program. American Journal of Preventive Medicine. 2010; 38(3 Suppl): S333-42. https://doi.org/10.1016/j.amepre.2009.11.019

[31] Flay BR. Mass media and smoking cessation: a critical review. American Journal of Public Health. 1987; 77(2): 153-60. https : //doi.org/10.2105/AJPH.77.2.153

[32] Hsu SM. New challenges and inspirations for future telephone survey research in Taiwan: The cell-phone-only factor [in Chinese]. [New Challenges and Inspirations for Future Telephone Survey Research in Taiwan: The Cell-Phone-Only Factor]. Survey Research-Method and Application. 2015; 34: 33-65. 